\title{
The value of near-peer teaching in the medical curriculum
}

This article was published in the following Dove Press journal:

Advances in Medical Education and Practice

\section{Vinay Jamnadas Sonagara \\ Swina Santhirakumaran Harkaran Singh Kalkat}

Department of Undergraduate Medicine, Faculty of Medicine, Imperial College London, London, UK
Correspondence: Vinay Jamnadas Sonagara

Department of Undergraduate Medicine, Faculty of Medicine, Imperial College London, Imperial College London Faculty Building, South Kensington, London, SW7 2AZ, UK

Tel/ Fax +44 7882230878

Emailvs2013@ic.ac.uk
According to the General Medical Council's guide for "Good Medical Practice", doctors are expected to partake in active mentoring roles and contribute to the education of other training doctors. ${ }^{1}$ This reflects the fact that medical education is an apprenticeship where the vertical transmission of knowledge from peers and colleagues contributes to a large proportion of the necessary clinical training. Therefore, peer teaching skills should be inculcated from an early stage. At Imperial College London, student-led societies encourage the cohort to take on mentoring and teaching roles to students in earlier years, in the form of near-peer teaching. However, this near-peer teaching largely remains a voluntary undertaking. Given the importance of these skills, there is an argument to be made that such tutoring schemes ought to form a more extensive and mandatory part of the medical syllabus.

Near-peer teaching can be mutually beneficial to both the tutor and tutee. The tutor can revisit previously learned topics while honing key proficiencies such as teaching skills, time management, and leadership. The tutee can benefit by acquiring advice from previously successful students with first-hand experience in exams and clinical placements. Previous literature has also highlighted the cognitive congruence hypothesis, ${ }^{2}$ where an equivalence in the knowledge or skill level between tutor and tutee ameliorates the transmission of that knowledge, thus highlighting the advantage of peer-to-peer interaction for tutees.

Adopting a near-peer teaching scheme may also provide benefits to the medical faculty. Studies have demonstrated that education is not compromised when a faculty teacher is substituted for a medical student. ${ }^{3,4}$ Thus, implementing near-peer teaching schemes may reduce teaching demands on the medical faculty. Near-peer teaching may also foster a pastoral relationship between tutors and tutees, enabling the provision of both educational and emotional support to medical students, thereby complementing the duties of the faculty. However, incorporating such schemes into the curriculum on a long-term basis may require the faculty to monitor and assess the quality of teaching, paradoxically increasing the burden.

Problems may also arise in ensuring standardization in the teaching offered by different tutors. Currently, some students may receive a better quality of teaching as compared to others, raising concern over the fairness of such teaching platforms. Although Imperial College London currently offers a 1-week teaching skills seminar during the fifth year of study, increased regularity and formal assessments of such efforts may improve standardization of near-peer teaching. Furthermore, as students themselves, 
tutors are in the process of accruing knowledge, rather than necessarily reflecting on it. This may compromise their ability to explain the finer conceptual points in the syllabus.

Medical education may be an intense and stressful time, and although enhancing time-management skills is an advantage of near-peer teaching schemes, it may add unnecessary pressures onto tutors, compromising their own learning. Meanwhile, tutees may use tutorials as a substitute for independent learning; while this empowers students with superficial knowledge, it precludes the need for a deeper reflection on the material. Taken together, poorly implemented schemes may hinder the overall learning of both tutor and tutee.

All in all, near-peer teaching schemes must ensure standardization in the quality of the teaching while acting in aid of, rather than in substitution for, independent learning and reflection. If implemented as such, they provide the opportunity for medical students to increase their learning resources, while simultaneously harvesting key skills that they will call upon throughout their future career.

\section{Disclosure}

The authors report no conflicts of interest in this work.

\section{References}

1. General Medical Council. Good Medical Practice. General Medical Council; 2013. Available from: http://www.gmcuk.org/static/documents/ content/GMP_.pdf. Accessed October 3, 2017.

2. Lockspeiser T, O'Sullivan P, Teherani A, Muller, J. Understanding the experience of being taught by peers: the value of social and cognitive congruence. Adv Health Sci Educ Theory Pract. 2008;13(3):361-372.

3. Tolsgaard M, Gustafsson A, Rasmussen M, HØiby P, Müller C, Ringsted C. Student teachers can be as good as associate professors in teaching clinical skills. Med Teach. 2007;29(6):553-557.

4. Burke J, Fayaz S, Graham K, Matthew R, Field M. Peer-assisted learning in the acquisition of clinical skills: a supplementary approach to musculoskeletal system training. Med Teach. 2007;29(6):577-582.
Advances in Medical Education and Practice

\section{Publish your work in this journal}

Advances in Medical Education and Practice is an international, peerreviewed, open access journal that aims to present and publish research on Medical Education covering medical, dental, nursing and allied health care professional education. The journal covers undergraduate education, postgraduate training and continuing medical education

\section{Dovepress}

including emerging trends and innovative models linking education, research, and health care services. The manuscript management system is completely online and includes a very quick and fair peer-review system. Visit http://www.dovepress.com/testimonials.php to read real quotes from published authors. 